\title{
Studies on Vision
}

\author{
THE NATURE OF THE RETINAL-OPSIN LINKAGE
}

\author{
By M. AKHTAR, P. T. BLOSSE* AND P. B. DEWHURST \\ Department of Physiology and Biochemistry, University of Southampton, SO9 5NH
}

(Received 25 June 1968)

\begin{abstract}
1. Convenient methods for the preparation of tritiated 11-cis-retinol, 11-cis-retinal and rhodopsin are described. Irradiation of labelled rhodopsin in the presence of sodium borohydride resulted in the irreversible binding of the retinyl moiety to the active site. Degradative studies established that the retinyl moiety in this reduced derivative of rhodopsin was attached to the $\epsilon$-amino group of lysine. In connexion with this investigation the synthesis of a number of $N$-retinylidene- and $N$-retinylamino acids was achieved. Derivatives of lysine with the retinyl moiety attached either to the $\alpha$-amino group or to the $\epsilon$-amino group were also synthesized and characterized. 2. It is suggested that the involvement of a charge-transfer interaction between the retinylidene chromophore and a suitable group $-\mathrm{X}$ or $-\mathrm{X} \cdot \mathrm{H}$ on the opsin best explains the spectroscopic properties of rhodopsin and other visual proteins.
\end{abstract}

Rhodopsin, the light-sensitive pigment of bovine retina, consists of an apoprotein, opsin, and a polyene aldehyde, 11-cis-retinal (Matthews, Hubbard, Brown \& Wald, 1963). In the present paper we report a convenient procedure for the introduction of tritium label into rhodopsin and describe experiments that have led to the conclusion that the polyene aldehyde in rhodopsin is attached to an $\epsilon$-amino group of lysine.

The presence of a Schiff-base linkage between 11-cis-retinal and opsin was originally proposed by Pitt, Collins, Morton \& Stok (1955). Convincing evidence in support of this hypothesis was provided by Akhtar, Blosse \& Dewhurst (1965) and Bownds \& Wald (1965).

It was shown that the bleaching of rhodopsin in the presence of sodium borohydride resulted in the irreversible bonding of the retinyl moiety with opsin, and the overall reaction was considered to involve the conversion of an imino linkage into a dihydro form as shown below by the equation $(\mathrm{I} a) \rightarrow(\mathrm{II} a)$ in Scheme 1 .

This stabilized chromophore has now been further investigated and we report a series of experiments that have resulted in the identification of the active site of rhodopsin. A part of this work has been reported in a preliminary form (Akhtar, Blosse \& Dewhurst, 1967; Blosse, 1967; see also Bownds,

* Present address: Unilever Research Laboratory, Colworth House, Sharnbrook, Bedford.
1967). We first describe the preparation of labelled rhodopsin and related compounds.

\section{RESULTS AND DISCUSSION}

Preparation of 11-cis-retinal. all-trans-Retinal in methanol was isomerized with white light and the isomers were separated by thin-layer chromatography. The fraction corresponding to 11-cis-retinal had spectroscopic properties similar to those described by Brown \& Wald (1956) for the 11-cis isomer. When this fraction was incubated in the presence of an excess of opsin, the rhodopsin formation indicated that $75-80 \%$ of the extinction at $380 \mathrm{~m} \mu$ in the retinal sample could be attributed to the 11-cis isomer.

Preparation of tritiated 11-cis-retinal. It was envisaged that a convenient procedure for the introduction of radioactivity into retinal was to reduce the aldehyde with tritiated sodium borohydride. The resulting tritiated retinol could then be reoxidized to retinal, retaining the tritium label at C-15. In the application of this procedure to 11-cis-retinal, a sample was reduced with tritiated sodium borohydride of high specific radioactivity $(6 \cdot 7 \mathrm{c} / \mathrm{m}-\mathrm{mole})$, and the retinol thus formed was oxidized with manganese dioxide, as originally described by Ball, Goodwin \& Morton (1948) and later developed into a convenient procedure by Wald (1948). The oxidized material possessed 
properties similar to those of the non-radioactive starting material and had a specific radioactivity of approx. $2.7 \times 10^{7}$ counts $/ \mathrm{min} . / \mu$ mole at $40 \%$ counting efficiency.

Synthesis of tritiated rhodopsin from tritiated 11-cis-retinal and the preparation of tritiated dihydrometarhodopsin II. A sample of tritiated 11-cisretinal was incubated with excess of opsin to regenerate rhodopsin. Residual retinal isomers were converted into the corresponding oximes by the addition of hydroxylamine (final concn. $0.05 \mathrm{M}$ ). The rhodopsin synthesized, $2.45 \mu$ moles, represented an incorporation of radioactivity of $6 \cdot 6 \times 10^{7}$ counts/ min. This sample was converted into dihydrometarhodopsin II by irradiation with white light in the presence of sodium borohydride and the solution was freeze-dried for subsequent purification.

At this stage it was essential to prove that the radioactive rhodopsin prepared above was not contaminated with random imino derivatives formed by non-enzymic reaction of 11-cis-retinal with available amino groups, and this was shown by two types of experiments. It was established<smiles>[R]=NCC=C(C)C=CC=C(C)C=CC1=C(C)CCCC1(C)C</smiles>

(I)

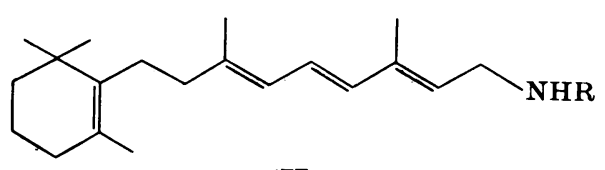

(II)

Scheme 1. (a) NR, protein; (b) NR, $\epsilon$-lysyl; (c) NR, $\alpha$-lysyl. that, under conditions similar to those required for rhodopsin formation at $\mathrm{pH} 6 \cdot 4$, all-trans-retinal gave no detectable Schiff-base (imino derivative) formation with lysine or with the free amino groups of poly-L-lysine. The hydroxylamine treatment included in the preparation of rhodopsin (see above) further ensured that any random Schiff bases formed during the enzymic reaction were irreversibly removed by the reaction:

$$
-\mathrm{C}: \mathrm{N}-+\mathrm{NH}_{2} \cdot \mathrm{OH} \rightarrow-\mathrm{C}: \mathrm{N} \cdot \mathrm{OH}+\mathrm{H}_{2} \mathrm{~N}-
$$

Experiments pertaining to this aspect are described in the Experimental section.

Further studies on the stabilized active site in dihydrometarhodopsin II (II $a$, Scheme 1) necessitated the synthesis of numerous retinylamino acids and related derivatives.

Preparation and properties of retinylideneamino acids, retinylamino acids and related derivatives. $N$-Retinylideneamino acids (structure of the type I, Scheme 1) were prepared by the reaction of all-transretinal with appropriate amino acids under basic conditions. The products possessed acid-base properties associated with imino derivatives of retinal, i.e. $\lambda_{\max }$ in acid $440-455 \mathrm{~m} \mu, \lambda_{\max }$ in alkali $360-370 \mathrm{~m} \mu$. When they were treated with sodium borohydride, a shift in wavelength maximum to $325 \mathrm{~m} \mu$ was observed, indicating the formation of the more stable dihydro derivatives, $N$-retinylamino acids (structure of the type II, Scheme 1). The chromatographic properties of these derivatives on thin layers are compared in Table 1.

It was particularly important (see below) to synthesize and characterize the derivatives of lysine with the retinyl moiety attached specifically either to the $\alpha$-amino or to the $\epsilon$-amino group. $\epsilon$-PHRL (totally reduced IIb, Scheme 1) and $\alpha$-PHRL*

* Abbreviations: $\alpha$-PHRL and $\epsilon$-PHRL, $\alpha$ - and $\epsilon-N$. perhydroretinyl-lysine respectively.

Table 1. $R_{F}$ values of retinylamino acids on thin-layer chromatography.

Details of the solvent systems and other experimental details are included in the Experimental section.

Retinylamino acid

$\epsilon-N$-Retinyl-lysine

$\epsilon-N$-Retinylornithine

$\alpha-N$-Retinylarginine

$\alpha-N$-Retinylhistidine

$\alpha-N$-Retinylaspartate

$\alpha-N$-Retinylalanine

$\alpha-N$-Retinyltyrosine

$\alpha-N$-Retinyl-leucine

$\alpha-N$-Retinyltryptophan

$\alpha-N$-Retinylphenylalanine
$R_{F}$ values

$\begin{array}{cccc}\text { Solvent 1 } & \text { Solvent 2 } & \text { Solvent 3 } & \text { Solvent 4 } \\ 0.48 & 0.55 & 0.63 & 0.55 \\ 0.48 & 0.55 & 0.63 & 0.55 \\ 0.48 & 0.52 & 0.63 & 0.58 \\ 0.53 & 0.58 & 0.68 & 0.61 \\ 0.46 & 0.45 & 0.57 & 0.63 \\ 0.54 & 0.64 & 0.70 & 0.65 \\ 0.56 & 0.58 & 0.69 & 0.68 \\ 0.62 & 0.74 & 0.75 & 0.68 \\ 0.59 & 0.69 & 0.73 & 0.65 \\ 0.61 & 0.73 & 0.75 & 0.70\end{array}$


(totally reduced IIc, Scheme 1) were prepared (see the Experimental section) and separated by the formation of their DNP derivatives. Table 2 shows the $R_{F}$ values of these derivatives in four different solvent systems.

є-PHRL gave one DNP derivative whereas $\alpha$-PHRL gave two derivatives. All three were clearly resolved by thin-layer chromatography. This technique could therefore differentiate $\alpha \cdot N$. retinyl-lysine from $\epsilon-N$-retinyl-lysine.

Elucidation of the structure of the DNP derivatives of $\epsilon-P H R L$ and $\alpha-P H R L$. Tritiated $N$-retinyl-lysine with a specific radioactivity of 49000 counts $/ \mathrm{min}$./ $\mu$ mole was first converted into $\epsilon \cdot$ PHRL, and its DNP derivative was then prepared. From the radioactivity and the extinction of the DNP derivative its molar extinction coefficient was calculated to be 25 500. Assuming a molar extinction coefficient for each DNP residue of approximately 15000, the value of 25500 obtained above allows us to formulate this compound as a bis-DNP derivative of $\epsilon$-PHRL. As it was considerably more difficult to measure the absolute molar extinction coefficients of the DNP derivatives of $\alpha$-PHRL, only the relative extinction coefficients were determined (Table 3 ). The two DNP derivatives $\left(R_{F} \quad 0.2\right.$ and 0.7$)$ of tritiated $\alpha$-PHRL were prepared and, from radio. activity and spectroscopic measurements, it was shown that the ratio of the molar extinction coefficient of the more polar $\left(R_{F} \mathbf{0 \cdot 2}\right)$ to that of the less polar $\left(R_{F} 0 \cdot 7\right)$ derivative was about $1: 1 \cdot 7$. This

Table 2. $R_{F}$ values of DNP derivatives on thin-layer chromatography

Details of the solvent systems and other experimental details are included in the Experimental section.

$\begin{array}{ccccc}\begin{array}{c}\text { DNP } \\ \text { derivative } \\ \text { of }\end{array} & \overbrace{\text { Solvent } A} & \text { Solvent } B & \text { Solvent } C & \text { Solvent } D \\ \alpha \text {-PHRL } & 0.2 & 0.05 & 0.2 & 0.2 \\ & 0.7 & 0.5 & 0.8 & 0.8 \\ \text { e-PHRL } & 0.5 & 0.25 & 0.7 & 0.7 \\ \text { Lysine } & 0.6 & 0.15 & 0.6 & 0.55\end{array}$

allows us to formulate the derivative with $R_{F} 0.2$ as $\epsilon$-DNP- $\alpha$-PHRL and the derivative with $R_{F} 0.7$ as $\alpha \epsilon$-bis-DNP- $\alpha$-PHRL. Although an alternative structure, $\alpha$-DNP- $\alpha$-PHRL, can be considered for the more polar $\left(R_{F} 0 \cdot 2\right)$ derivative, we consider that this is unlikely, however, because the dinitrophenylation of the unsubstituted $\epsilon$-amino group should be faster than that of the substituted $\alpha$-amino group. Consistent with these structural assignments is the fact that increasing the 1 -fluoro2,4-dinitrobenzene reaction time gave an increased percentage of the bis-DNP derivative.

Purification of tritiated dihydrometarhodopsin II. The stage was now set for the elucidation of the active site of rhodopsin. The freeze-dried solid containing tritiated dihydrometarhodopsin II was washed with methanol and ether to remove the major radioactive contaminant, retinal oxime. Radioactivity and spectroscopic measurements of the washings indicated that not less than $95 \%$ of the retinal oxime had been removed. This was later confirmed by thin-layer chromatography of the washed solid, which was shown to contain a minimum of $92 \%$ of the radioactivity in the protein fraction. This solid (A) was used in all subsequent experiments without further purification. The radioactive protein in solid (A) probably represents a denatured form of opsin firmly bound to the radioactive retinyl moiety. Therefore, although reference to this component as dihydrometarhodopsin II is not strictly correct, for the sake of simplicity this definition will be retained in all further discussion.

Basic hydrolysis of tritiated dihydrometarhodopsin II and analysis of radioactive components. A sample of solid (A) was hydrolysed with $5 \mathrm{~N}$-sodium hydroxide in the presence of $\epsilon-N$-retinyl-lysine (IIb, Scheme 1). The hydrolysate was neutralized and then analysed for radioactive components by thin-layer chromatography. One major peak was present, which corresponded to the $\epsilon-N$-retinyllysine fraction. When the hydrolysate was freezedried and extracted with chloroform-methanol to obtain the retinyl-amino acids, the extract contained $30-50 \%$ of the original radioactivity. Thin-layer chromatography of the extracts in five different

Table 3. Spectroscopic and radioactive results with the DNP derivatives of tritiated $\alpha-P H R L$

$R_{F}$ values refer to thin-layer chromatographic separation in chloroform-methanol-acetio acid $(95: 5 ; 1$, by vol.) (solvent $A$ ). Spectra were recorded in $0 \cdot 1 \mathrm{~N}$-acetic acid in methanol, Radioactivity measurements were corrected for quenching by internal standardization. Other experimental details are given in the text.

\begin{tabular}{|c|c|c|c|c|c|c|}
\hline $\begin{array}{l}\text { DNP } \\
\text { derivative }\end{array}$ & $\begin{array}{l}R_{F} \text { of } \mathrm{DNP} \\
\text { derivative }\end{array}$ & $\lambda_{\max .}(\mathbf{m} \mu)$ & $E_{\max }$ & $\begin{array}{c}\text { Radioactivity } \\
\text { (counts/min./ml.) }\end{array}$ & $E_{\max .} / 1000$ counts $/ \mathrm{min}$ & $\begin{array}{l}\text { Ratio of molar extinction } \\
\text { coefficients }[(\mathrm{i}):(\mathrm{ii})]\end{array}$ \\
\hline (i) & $0 \cdot 2$ & 347 & $0 \cdot 47$ & 5000 & 0.094 & $1: 1 \cdot 7$ \\
\hline (ii) & $0 \cdot 7$ & 354 & $1 \cdot 63$ & 10120 & $0 \cdot 161$ & $1: 1 \cdot 6$ \\
\hline
\end{tabular}




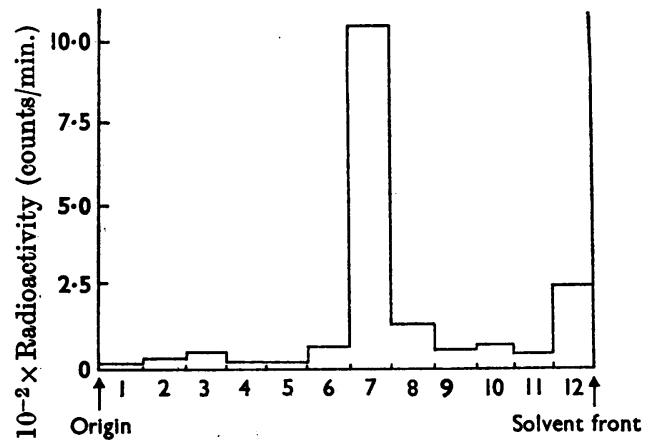

Fraction no.

Fig. 1. Distribution of radioactivity in the extract of hydrolysed tritiated dihydrometarhodopsin II. The sample was separated by thin-layer chromatography in chloroformmethanol-aq. $\mathrm{NH}_{3}$ soln. (sp.gr. 0.88)-water (4:4:1:1, by vol.) (solvent 3). Fraction 7 corresponded to $\epsilon-N$-retinyllysine and contained $56 \%$ of the total radioactivity on the chromatogram.

solvent systems showed that $50-65 \%$ of the radioactivity was associated with the $\epsilon-N$-retinyl-lysine fraction. A typical chromatographic separation is shown in Fig. 1.

In a control experiment it was shown that the hydrolysis of tritiated $\epsilon-N$-retinyl-lysine gave some degradation products, which ran ahead of $\epsilon-N$. retinyl-lysine. These degradation products could account for similar components (representing $15-25 \%$ of the total radioactivity) present in the hydrolysed protein extracts. For this reason only the major radioactive peak in the region of $\epsilon-N$ retinyl-lysine was investigated further.

To elucidate the nature of the radioactive component, the extract was stabilized by hydrogenation. Thin-layer chromatography of the resultant solution showed again that $45-65 \%$ of the radioactivity was in the region corresponding to $\epsilon$-PHRL. This fraction was isolated by preparative thick-layer chromatography and treated with 1-fluoro-2,4dinitrobenzene. The ether extract of the basic reaction mixture contained $94 \%$ of the total radioactivity and, of this amount, $75-85 \%$ was located in the region of the DNP derivative of $\epsilon$-PHRL. No radioactivity could be detected in the regions corresponding to the DNP derivatives of $\alpha$-PHRL (totally reduced II $c$, Scheme 1 ).

These results prove that the derivative of rhodopsin that is reduced with sodium borohydride contains the retinyl moiety attached to an $\epsilon$-amino group of lysine.

The sodium borohydride method for stabilizing the rhodopsin molecule (Akhtar et al. 1965; Bownds \& Wald, 1965) has been used to achieve a purification of this protein (Shields, Dinovo, Henriksen, Kimbel \& Millar, 1967).

Comments on the absorption spectra of visual pigments and related compounds. Irradiation of rhodopsin with visible light in aq. 1-2\% digitonin solution results in the formation of all-transretinal and opsin through a number of unstable intermediates (rhodopsin $\rightarrow$ pre-lumirhodopsin $\rightarrow$ lumirhodopsin $\rightarrow$ metarhodopsin $I \rightarrow$ metarhodopsin II $\rightarrow$ all-trans-retinal +opsin) that possess characteristic absorption spectra (Matthews et al. 1963). This transformation is accompanied by a hypsochromic shift of about $118 \mathrm{~m} \mu$, the absorption maxima of all-trans-retinal and rhodopsin being $380 \mathrm{~m} \mu$ and $498 \mathrm{~m} \mu$ respectively. This remarkable shift has hitherto not been satisfactorily explained.

We have shown above that the retinyl moiety at the metarhodopsin II stage is attached to an $\epsilon$-amino group of lysine. Assuming that the same or a similar primary amino group of a saturated side chain is involved in the binding of 11-cis-retinal in rhodopsin, then any theory for explaining the absorption maxima of visual pigments that involves the concept of the elongation of the chromophoric chain may be excluded. We have therefore advanced an alternative hypothesis, which requires that the $N$-retinylidene chromophore and a suitably situated group $-\mathrm{X}$ or $-\mathrm{X} \cdot \mathrm{H}$ in rhodopsin interact to give rise to an intramolecular charge-transfer transition (some aspects of this problem were discussed by Akhtar et al. 1965).

On the basis of this hypothesis the overall change of $\lambda_{\max }$ from $500 \mathrm{~m} \mu$ to $380 \mathrm{~m} \mu$ on the bleaching of rhodopsin is envisaged to occur because of the dislocation of the two groups, and this phenomenon is discussed in detail below.

The involvement of the 11-cis double bond in the cis-trans isomerization process accompanying the bleaching of visual proteins has been recognized for a considerable time. However, the demonstration of a Schiff-base linkage in rhodopsin has necessitated the consideration of an additional syn-anti isomerization about the $>\mathrm{C}: \mathrm{N}$ - linkage, and this is shown below:<smiles>[R]C=NC=NC</smiles>

In the rigid protein structure, the photo-induced 11-cis $\rightarrow$ 11-trans isomerization can proceed by one of the two possible mechanisms, involving a movement of either the C-10-C-11 bond or the C-12-C-13 bond through $120^{\circ}$. If the photoisomerization occurred through the movement of the C-10-C-11 bond, then the lipophilic $\beta$-ionone residue would occupy a new site on the protein (III $\rightarrow$ IV, Scheme 2), and therefore to accommodate 


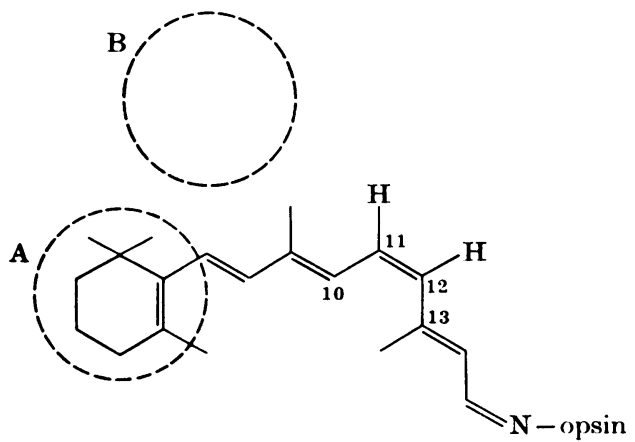

(III)

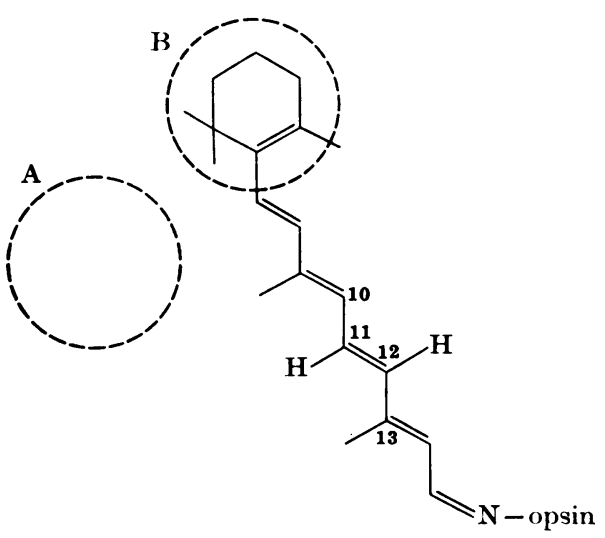

(IV)

Scheme 2. Conversion (III) $\rightarrow$ (IV) is shown to occur by the movement of the $\mathrm{C}-10-\mathrm{C}-11$ bond through $120^{\circ}$; this results in the displacement of the $\beta$-ionone moiety from region $A$ in structure (III) to region B in structure (IV). In the above diagram the postulated group $-\mathrm{X}$ or $-\mathrm{X} \cdot \mathrm{H}$ responsible for the charge-transfer transition has not been shown.

this residue in the new environment a con. formational change in the protein might occur. This would disturb the critical distance between the $N$-retinylidene chromophore and the group $-\mathrm{X}$ or $-\mathbf{X} \cdot \mathbf{H}$ on opsin, whose interaction is responsible for the change-transfer spectrum. The second possibility involving the movement of the C-12-C-13 bond would allow the lipophobic $>\mathrm{C}: \mathrm{N}$ - region of the molecule to occupy a new position on the protein surface. This movement would be expected to result in a considerable twisting of the bonds that, however, can be partly relieved through a concomitant isomerization about the $>\mathrm{C}: \mathrm{N}-$ linkage and partly by the flexibility provided by the chain of singly bonded atoms in the lysyl residue. The overall process is shown $(\mathrm{V} \rightarrow \mathrm{VI}$, Scheme 3$)$. Available experimental evidence does not allow a choice between these two possibilities, but in both cases the overall requirements accompanying bleaching are twofold. First, there must be a separation of the group $-\mathrm{X}$ or $-\mathrm{X} \cdot \mathrm{H}$ from the $>\mathrm{C}: \mathrm{N}$ - linkage, thus resulting in the loss of chargetransfer interaction, and, secondly, the $>\mathrm{C}: \mathrm{N}-$ linkage must be exposed so that in its new environment it can undergo chemical reactions, e.g. nucleophilic attack by water resulting in hydrolysis or by sodium borohydride resulting in the formation of the dihydro derivative.

The intermediates of the bleaching of rhodopsin, i.e. pre-lumirhodopsin, lumirhodopsin etc., have only been observed at low temperatures, and since the rate of molecular rotation of chemical bonds becomes lower with decreasing temperature it is proposed that these species simply represent the freezing of the intermediary stages between the two extremes shown by structures (V) and (VI) (Scheme 3). The bathochromic shift of $45 \mathrm{~m} \mu$ involved when rhodopsin is photoisomerized to pre-lumirhodopsin at about $-194^{\circ}$ is particularly noteworthy. In terms of the present hypothesis, this is due to the charge-transfer interaction of a superior all-transretinyl chromophore which is still situated favourably with respect to the group $-\mathrm{X}$ or $-\mathrm{X} \cdot \mathbf{H}$.

In order to evaluate the possible involvement of the $N$-retinylidene chromophore in a charge-transfer transition, we measured the absorption spectra of $N$-retinylidenemethylammonium iodide and have compared it with that of a reference compound, $N$-retinylidenemethylammonium bromide. Table 4 shows that in all solvents the absorption maxima of the iodide were at higher wavelengths than those of the corresponding bromide. Since in both compounds the chromophoric group is identical, the bathochromic shift noted for the iodides is probably due to an intermolecular charge-transfer complex. It is to be expected that, compared with the bromide ion, the iodide ion would be more efficient in the formation of charge-transfer complexes (Dewhurst 1967).

\section{EXPERIMENTAL}

all-trans-Retinal and all-trans-retinol were purchased from Eastman-Kodak Ltd., Kirkby, Liverpool. Digitonin was supplied by Hopkin and Williams Ltd., Chadwell Heath, Essex, and $10 \%$ palladium on charcoal by Johnson, Matthey and Co. Ltd., London, E.C. 1. 2-(4-tert.-Butylphenyl)-5-(4-biphenylyl)-1-oxa-3,4-diazole scintillator was obtained from Ciba (A.R.L.) Ltd., Duxford, Cambs. Silica gel for chromatography (Merck) was purchased from Camlab Ltd., Cambridge, and poly-L-lysine hydrobromide (approx. molecular weight 2600) from Sigma Chemical Co. (distributors, R. N. Emanuel Ltd., London, S.E. 1). Tritiated sodium borohydride was supplied by The Radiochemical Centre, Amersham, Bucks. All other chemicals were obtained from British Drug Houses Ltd., Poole, Dorset. 


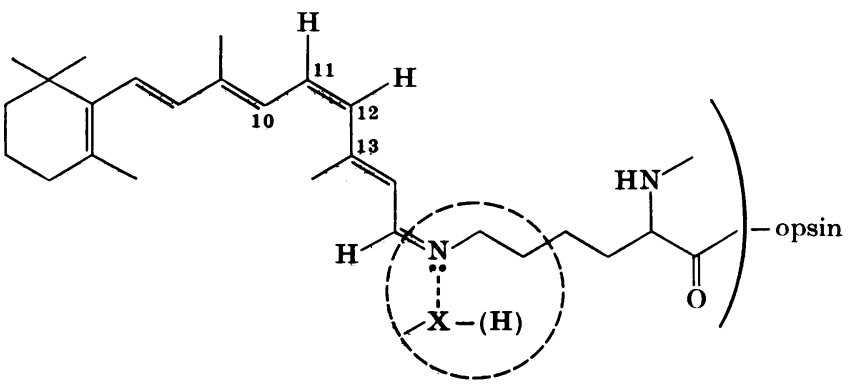

(V)

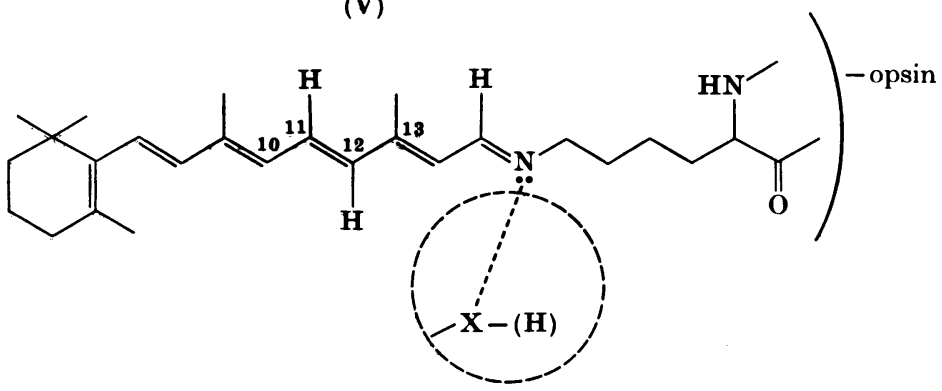

(VI)

Scheme 3. Conversion (V) $\rightarrow$ (VI) illustrates the second possibility involving the movement of the C-12-C-13 bond through $120^{\circ}$. The circle in structures (V) and (VI) is the region of the protein that contains group $-\mathrm{X}$ or $-\mathrm{X} \cdot \mathrm{H}$. It is noteworthy that in structure (VI) the chromophoric group is dislocated from the region of group $-\mathrm{X}$ or $-\mathbf{X} \mathbf{H}$.

Table 4. Absorption maxima of $\mathrm{N}$-retinylidenemethylammonium iodide and bromide in various solvents

For experimental details, see the text.

\begin{tabular}{|c|c|c|}
\hline & & \\
\hline & $\mathrm{I}^{-}$ & $\mathrm{Br}^{-}$ \\
\hline Compound $\ldots$. & & \\
\hline Solvent & & \\
\hline Chloroform & 485 & 477 \\
\hline Dichloromethane & 489 & 484 \\
\hline Benzene & 455 & 451 \\
\hline Methanol & 448 & 444 \\
\hline Dioxan & 446 & 445 \\
\hline Diethyl ether & 445 & 442 \\
\hline
\end{tabular}

Radioactive measurements were made on a Beokman CPM 200 liquid-scintillation system. Visible- and ultraviolet-absorption spectra were reoorded either on a Hilger and Watts Ultrascan 11999 (mark 2) recording spectrophotometer or on a Unicam SP.800 with an 8P.825 automatic sample changer.

Thin-layer chromatography. Analytical separations were made on $10 \mu$ layers of silica gel G. Wedge-shaped layers of
$10-80 \mu$ thickness were used in preparative separations of amounts up to $5 \mathrm{mg}$.; the samples were applied as a band at the thick end of the layer. Larger amounts were separated on $0.2 \mathrm{~cm}$. layers of silica gel $\mathrm{H}$. All plates were developed by ascending ohromatography for at least $15 \mathrm{~cm}$. with the following solvents: solvent 1, butan-2-one-2-methylpropan2-ol-aq. $\mathrm{NH}_{3}$ soln. (sp.gr. 0-88)-water (18:18:7:9, by vol.); solvent 2, propan,1-ol-aq. $\mathrm{NH}_{3}$ soln. (sp,gr. 0.88) $(2: 1, \mathrm{v} / \mathrm{v})$; solvent 3, chloroform-methanol-aq. $\mathrm{NH}_{3}$ soln. (sp.gr. 0.88)water $(4: 4: 1: 1$, by vol.); solvent 4 , butan-1-ol-acetic acidwater $(3: 1: 1$, by vol.); solvent 5 , propan-1-ol-water $(2: 1, \mathrm{v} / \mathrm{v})$.

Detection of compounds on chromatograms. Fluorescent compounds were detected under ultraviolet light. Ultraviolet-absorbing compounds were separated on fluorescent layers (silica gel $\mathrm{GF}_{254}$ ) and analysed under ultraviolet light. Ninhydrin-positive material was detected by spraying the layer with $0.25 \%(\mathrm{w} / \mathrm{v})$ ninhydrin in acetone and heating it at $110^{\circ}$ for $5 \mathrm{~min}$. Layers developed in solvent syctems containing aq. $\mathrm{NH}_{3}$ soln. were heated at $110^{\circ}$ for $15 \mathrm{~min}$. before being sprayed.

Measurement of radioactivity. Non-aqueous samples $(0 \cdot 1-0 \cdot 2 \mathrm{ml}$.) were added to $5-10 \mathrm{ml}$. of a liquid scintillator containing 2-(4-tert.-butylphenyl)-5-(4-biphenylyl)-1-oxa3,4-diazole in toluene (8g./1,). Aqueous samples (0.1-0.2 ml,) were added either to $5-15 \mathrm{ml}$. of a scintillator containing 2-(4-tert.-butylphenyl)-5-(4-biphenylyl)-1 -oxa-3,4-diazole $(8 \mathrm{~g} . / \mathrm{l}$.$) and naphthalene (60 \mathrm{~g} . / \mathrm{l}$.) in A.R. dioxan or to 10-15 ml. of 2-(4-tert.-butylphenyl)-5-(4-biphenylyl)-1-oxa3,4-diazole (8g./l.) in methanol-toluene $(1: 3, v / v)$.

Preparation of $6-\mathrm{N}$-retinylidene-lysine and -ornithine. 
L-Lysine hydrochloride $(32.5 \mathrm{mg}$.) or L-ornithine hydrochloride $(29 \mathrm{mg}$.) was dissolved in $1 \mathrm{ml}$. of water, and triethylamine was then added to $\mathrm{pH} 8 \cdot 5-9 \cdot 0$. Then $50 \mathrm{mg}$. of all-trans-retinal in $10 \mathrm{ml}$. of methanol was added to the amino acid solution and the mixture was left under $\mathrm{N}_{2}$ in the dark for about $30 \mathrm{~min}$. Schiff-base formation was measured by adjusting a sample to $\mathrm{pH} 2 \cdot 0$ with $6 \mathrm{~N}-\mathrm{HCl}$ to give the typical protonated species with absorption maximum at $440 \mathrm{~m} \mu$. When this was equal in extinction to the corresponding alkaline $(\mathrm{pH} 10 \cdot 0)$ maximum at $360 \mathrm{~m} \mu$, the reaction was considered to be complete.

Preparation of $\alpha \cdot \mathrm{N}-$ retinylideneamino acids. Derivatives of L-arginine, L-histidine, L-aspartate, L-alanine, L-tyrosine, L-leucine, L-tryptophan and L-phenylalanine were prepared by the following method, A portion (1 mg.) of all-transretinal in $5 \mathrm{ml}$. of methanol and $1 \mathrm{ml}$. of $1 \mathrm{~N}-\mathrm{KOH}$ were mixed with $2 \mathrm{ml}$. of an aqueous solution containing the amino acid. The molar ratio of the amino acid to all-transretinal was 10:1. The mixture was left for $6 \mathrm{hr}$. in the dark and then analysed for Schiff-base formation as described for $\epsilon-N$-retinylidenelysine.

Preparation of N-retinylamino acids. N-Retinylideneamino acids were reduced in methanolic solutions with $\mathrm{NaBH}_{4}$ (10-20mg.). A shift in the absorption maximum to approx. $325 \mathrm{~m} \mu$ was indicative of the formation of the $N$-retinylamino acid.

Partial purification of N-retinylamino acids. Methanolic solutions of $N$-retinylamino acids were diluted with 2 vol. of water and extracted with three $20 \mathrm{ml}$. lots of light petroleum (b.p. $40-60^{\circ}$ ) to remove retinol. The aqueous layer was then extracted with three $20 \mathrm{ml}$. lots of chloroform and the extract containing the $N$-retinylamino acid was evaporated to dryness in vacuo. The solid was finally taken up in methanol and stored at $-10^{\circ}$ in darkness.

Preparation of $\epsilon-P H R L$. A sample (10-20mg.) of $\epsilon-N$, retinyl-lysine in $15 \mathrm{ml}$. of methanol (measured by assuming a molar extinction coefficient in methanol of 52000 ) was adjusted to $\mathrm{pH} 7.0$ with triethylamine or $1 \mathrm{~N}-\mathrm{HCl}$. This solution was added to a suspension of pre-reduced $10 \%$ palladium on charcoal ( $200 \mathrm{mg}$.) in methanol (10 ml.). The mixture was stirred vigorously under $\mathrm{H}_{2}$ for $1-2 \mathrm{hr}$.; the uptake of $\mathrm{H}_{2}$ was within $10 \%$ of the calculated volume, assuming an uptake at $20^{\circ}$ of $119 \mathrm{ml}$. of $\mathrm{H}_{2} / \mathrm{m}$-mole of $\epsilon-N$-retinyl-lysine or $0.29 \mathrm{ml}$. $/ \mathrm{mg}$. The solution was filtered and the catalyst was washed with methanol (approx. $20 \mathrm{ml}$.). The filtrate gave no absorption at ultraviolet or visible wavelengths. Thin-layer chromatographic analysis in amino acid solvent systems revealed the presence of a non-fluorescent ninhydrin-positive component with $R_{F}$ identical with that of $\epsilon$ - $N$-retinyl-lysine. These properties were consistent with the formation of $\epsilon$-PHRL. The sample was homogeneous by the chromatographic analysis described above.

Preparation of $\epsilon-\mathrm{N}$-benzyloxycarbonyl- $\alpha-N$-retinyl-lysine. A portion (100mg.) of $\epsilon-N$-benzyloxycarbonyl-lysine was dissolved in $15 \mathrm{ml}$. of methanol containing $0.1 \mathrm{ml}$, of $7.5 \mathrm{~N}$ $\mathrm{NaOH}$. Then $50 \mathrm{mg}$. of all-trans-retinal in $5 \mathrm{ml}$. of methanol was added, giving a molar ratio of $\epsilon-N$-benzyloxycarbonyllysine to all-trans-retinal of $2: 1$. The mixture was left in the dark for 2-3 hr., and Schiff-base formation was measured by the acid-base properties, as described in the preparation of $\epsilon-N$-retinylidene-lysine. When more than $50 \%$ of the retinal had reacted, $\mathrm{NaBH}_{4}(20 \mathrm{mg}$.) was added to give the dihydro derivative, $\epsilon-N$-benzyloxycarbonyl- $\alpha-N$-retinyl- lysine. Tritium could be incorporated at this stage by using tritiated $\mathrm{NaBH}_{4}$.

Preparation of $\alpha-P H R L$. $\epsilon-N$-Benzyloxycarbonyl- $\alpha-N$ retinyl-lysine, prepared as described above, was adjusted to $\mathrm{pH} 7 \cdot 0$ with $1 \mathrm{~N}-\mathrm{HCl}$ and hydrogenated for $1 \mathrm{hr}$. by the method described in the preparation of 6 -PHRL. After this period, $2 \mathrm{ml}$. of acetic acid was added to the solution and the hydrogenation continued for a further $1 \mathrm{hr}$. The entire procedure not only removed the benzyloxycarbonyl moiety but also totally reduced the polyene chain. The filtered solution gave no absorption above $250 \mathrm{~m} \mu$, and thin-layer chromatographic analysis in solvent 3 showed the presence of a ninhydrin-positive non-fluorescent component with $R_{F}$ marginally lower than that of $\epsilon$-PHRL. There was no indication of the presence of $\epsilon$-PHRL or of the starting material, $\epsilon-N$-benzyloxycarbonyl-lysine, and therefore these results were consistent with the formation of $\alpha$-PHRL. Trace amounts of a similar component were sometimes detectable in $\epsilon$-PHRL preparations.

Preparation of DNP derivatives of $\alpha-P H R L$ and $\epsilon-P H R L$. Samples (approx. 5-10mg.) of $\alpha$-PHRL or $\epsilon$-PHRL in methanol $(10-15 \mathrm{ml}$.) were mixed with $1.0 \mathrm{ml}$. of saturated $\mathrm{NaHCO}_{3}$ solution, resulting in a final $\mathrm{pH}$ of approx. 8.5-9.0. Then $0.05 \mathrm{ml}$. of 1-fluoro-2,4-dinitrobenzene in $1 \mathrm{ml}$. of methanol was added, and the mixture was shaken under $\mathrm{N}_{2}$ for $1 \frac{1}{2}-2 \mathrm{hr}$. in the dark. The reaction mixture was then diluted with $1 \frac{1}{2}-2$ vol. of water and extracted with five $15 \mathrm{ml}$. lots of ether. The ether extract containing the DNP derivatives was dried over anhydrous $\mathrm{Na}_{2} \mathrm{SO}_{4}$, filtered and evaporated in vacuo to $1-2 \mathrm{ml}$. The concentrate was separated by thick-layer chromatography in methanolchloroform $(1: 4, v / v)$ to remove excess of reagent and by-products. The lower intense yellow band was eluted with methanol and the solution was retained for further analysis. Samples were applied to analytical thin layers and developed in one of the following solvent systems : solvent $A$, chloroform-methanol-acetic acid ( $95: 5: 1$, by vol.); solvent $B$, benzene-pyridine-acetic acid (40:10:1, by vol.); solvent $C$, chloroform-2-methylbutan-2-ol-acetic acid (70:30:3, by vol.); solvent $D$, chloroform-benzyl alcoholacetic acid (70:30:3, by vol.). The $R_{F}$ values are shown in Table 2.

Preparation of a mixture of retinal isomers. all-transRetinal (30 mg.) in methanol $(30 \mathrm{ml}$.) was irradiated with white light from two $175 \mathrm{w}$ Phillips Photolita lamps at a distance of $1 \mathrm{ft}$. for $30 \mathrm{~min}$. The solution was maintained at less than $-10^{\circ}$ throughout this procedure. The isomerized solution showed a $25 \%$ decrease in the extinction at 375$385 \mathrm{~m} \mu$ and a shift of $2-3 \mathrm{~m} \mu$ to shorter wavelengths, these changes being consistent with the formation of a mixture of retinal isomers. The isomerized preparation was stored in darkness under $\mathrm{N}_{2}$ at $-65^{\circ}$ until required.

Isolation of 11-cis-retinal from the mixture of isomers, All operations were performed under dim red light (Kodak Wratten series I) and at temperatures less than $10^{\circ}$ whenever practicable. Exposure of the sample to atmospherio $\mathrm{O}_{2}$ was kept to a minimum.

Isomers were separated on an analytical scale by conventional thin-layer chromatography. Four distinct bands were obtained when layers were developed two or three times in either of the following solvent systems: solvent $A^{\prime}$, light petroleum (b.p. 30-40 $0^{\circ}$-nonan-2-one (11:1, v/v); solvent $B^{\prime}$, light petroleum (b.p. 30-40 )-acetone (100:3, $\mathrm{v} / \mathrm{v}$ ). The bands represented, in increasing order of polarity, 
the following isomers: (i) 11,13-di-cis, (ii) 11-cis and 13-cis, (iii) 9,13-di-cis and (iv) all-trans and 9-cis. The $R_{F}$ values were in the range $0.5-0.6$ on most chromatograms. The band corresponding to 11-cis-retinal was confirmed by co-chromatography with a standard sample.

Separation of the isomers on a preparative scale was achieved by using preparative thin layers. The layers were developed three times in solvent $B^{\prime}$. Solvent $A^{\prime}$ was not employed for these separations because difficulty was encountered in removing the solvent nonan-2-one. The chromatogram was inspected under dim white light and the 11-cis-retinal fraction removed. The isomer was eluted from the silica gel with methanol (2-3 ml.) and the eluate evaporated to dryness to remove traces of light petroleum. The sample was finally taken up in methanol $(2 \mathrm{ml}$.) and stored in darkness under $\mathrm{N}_{2}$ at $-65^{\circ}$.

Reduction of retinal isomers with sodium borohydride. Samples containing up to $20 \mathrm{mg}$. of retinal in methanol (2 ml.) were treated with excess of $\mathrm{NaBH}_{4}(5 \mathrm{mg}$.). The formation of the corresponding retinol isomer was confirmed by the appearance of an absorption maximum at $320-325 \mathrm{~m} \mu$ and a loss in extinction at $375-380 \mathrm{~m} \mu$. The reaction mixture was acidified with acetic acid to $\mathrm{pH} 6.0$ to neutralize the excess of $\mathrm{NaBH}_{4}$. Saturated $\mathrm{NaHCO}_{3}(4 \mathrm{ml}$.) was then added and the retinol extracted with three $2 \mathrm{ml}$. lots of light petroleum (b.p. $40-60^{\circ}$ ). The extract was washed with three $3 \mathrm{ml}$. lots of water, dried over $\mathrm{Na}_{2} \mathrm{SO}_{4}$, filtered and evaporated to dryness in vacuo. The solid was redissolved in $2 \mathrm{ml}$. of light petroleum (b.p. $40-60^{\circ}$ ). The recovery of retinol was greater than $\mathbf{7 0} \%$.

Reduction of 11-cis-retinal with tritiated sodium borohydride. 11-cis-Retinal (15 mg.) in methanol (3ml.) was treated with tritiated $\mathrm{NaBH}_{4}(6 \cdot 7 \mathrm{c} / \mathrm{m}$-mole), giving a $25-30 \%$ reduction to the alcohol. The excess of retinal was reduced with non-radioactive $\mathrm{NaBH}_{4}$, and the tritiated 11-cis-retinol was extracted as described above.

Oxidation of retinol isomers with manganese dioxide. Precipitated $\mathrm{MnO}_{2}$ was prepared by the method of Attenburrow et al. (1952). Oxidation of retinol isomers was achieved by using the column-chromatographic technique described by Wald (1948). For the oxidation of 5-10 mg. of retinol, $270 \mathrm{mg}$. of $\mathrm{MnO}_{2}$ in light petroleum (b.p. 40-60 $)$ was packed in a column $(1 \mathrm{~cm} . \times 6 \mathrm{~cm}$.) to give a bed height of $1 \mathrm{~cm}$. For less than $5 \mathrm{mg}$. of retinol, $150 \mathrm{mg}$. of $\mathrm{MnO}_{2}$ was used. The retinol sample in approx. $2 \mathrm{ml}$. of light petroleum (b.p. $40-60^{\circ}$ ) was eluted with light petroleum at a flow rate of 1-2ml./min. Samples of the eluate were analysed in methanol during the experiment. Eluates containing significant absorption at $320-325 \mathrm{~m} \mu$ were reoxidized on the same column. On occasions the oxidized material was purified by preparative thin-layer chromatography.

Oxidation of (tritiated) 11-cis-retinol. Samples were oxidized as described above, but all operations were performed under dim red light, and eluates were collected in tubes surrounded by solid $\mathrm{CO}_{2}$. Elution time was kept to a minimum. The oxidized material was purified by preparative thin-layer chromatography.

Preparation of rhodopsin. Cattle eyes were obtained fresh from a local abattoir. The retinae were removed in daylight and then placed in darkness for $1 \mathrm{hr}$. at room temperature. The dark-adapted retinae, over solid $\mathrm{CO}_{2}$, were transported to the laboratory and finally stored at $-65^{\circ}$.

The outer segments of the rods were obtained by slight modifications of the method of Matthews et al. (1963). A temperature of $5^{\circ}$ was maintained throughout the separation, and all operations were performed under dim red light. A batch of 100 dark-adapted retinae was ground in a mortar to a fine paste. To this, approx. $150-200 \mathrm{ml}$. of $45 \%(\mathrm{w} / \mathrm{v})$ sucrose in $0.067 \mathrm{M}$-sodium phosphate buffer, $\mathrm{pH} 7.0$, was slowly added, and the blended mixture was centrifuged at $25000 \mathrm{~g}$ for $30 \mathrm{~min}$. The surface layer of rod outer segments was scraped off, the lower sucrose layer being excluded if possible. The rods were washed with 3 vol. of $0.067 \mathrm{M}$-sodium phosphate buffer, $\mathrm{pH} 7 \cdot 0$, and centrifuged at $38000 \mathrm{~g}$ for $15 \mathrm{~min}$. The solid was ground with $25-50 \mathrm{ml}$. of $40 \%(\mathrm{w} / \mathrm{v})$ sucrose in $0.067 \mathrm{~m}$-sodium phosphate buffer, $\mathrm{pH} 7.0$, and centrifuged at $38000 \mathrm{~g}$ for $30 \mathrm{~min}$. The surface layer of rods was scraped off and washed three times with water, being centrifuged at $38000 \mathrm{~g}$ for $30 \mathrm{~min}$. after each washing. The solid was suspended in approx. $20 \mathrm{ml}$. of aq. $4 \%(\mathrm{w} / \mathrm{v})$ potassium alum solution and left for $15 \mathrm{~min}$. The solution was then diluted with 2 vol. of water and centrifuged at $38000 \mathrm{~g}$ for $5 \mathrm{~min}$. The rod segments were washed once with water and twice with $0.067 \mathrm{M}$-sodium phosphate buffer, pH 7.0. The segments were freeze-dried and washed with light petroleum (b.p. $40-60^{\circ}$ ), although the latter procedure was occasionally omitted. The dried segments were suspended in $2 \%(\mathrm{w} / \mathrm{v})$ digitonin in $0.05 \mathrm{M}$-sodium phosphate buffer, $\mathrm{pH} \mathrm{6 \cdot 4}$, and shaken for $1-3 \mathrm{hr}$. at room temperature to solubilize rhodopsin. The solution was then centrifuged at $38000 \mathrm{~g}$ for $30 \mathrm{~min}$. and the supernatant containing rhodopsin was retained.

On occasions the rhodopsin was resistant to extraction, probably as a result of aging, and the technique described by Abrahamson, Erhardt \& Oestroy (1966) was employed. The suspension of rod outer segments in buffered $2 \%(w / v)$ digitonin was stirred vigorously for $3 \mathrm{hr}$. at $5^{\circ}$ and then warmed to $30^{\circ}$, this temperature being maintained for $5 \mathrm{~min}$. The solution was then cooled to $5^{\circ}$ and centrifuged, and the supernatant was retained. The $E_{400} / E_{500}$ ratios of the rhodopsin extracts were normally in the range $0 \cdot 26-0 \cdot 35$.

Preparation of opsin. This preparation was similar to that described for rhodopsin except that, preceding the treatment with alum, the rod outer segments were irradiated with intense white light. Subsequent stages, as described for rhodopsin, were performed under white light. Opsin was extracted at $0-5^{\circ}$ with $2 \%(w / v)$ digitonin in $0.067 \mathrm{M}$-sodium phosphate buffer, pH6.4. The suspension was stirred vigorously for 1-2hr. and then centrifuged to give a supernatant containing opsin. Extracts were stored at $-5^{\circ}$ and normally used within $24 \mathrm{hr}$. The concentration of active opsin (see under 'Regeneration of rhodopsin from opsin and 11-cis-retinal') could then be directly related to the extinction at $276-280 \mathrm{~m} \mu$, and this criterion was then used in all subsequent experiments.

Regeneration of rhodopsin from opsin and 11-cis-retinal. A portion (10 mg.) of digitonin was dissolved in $1 \mathrm{ml}$. of methanol and to this was added a concentrated sample of 11-cis-retinal in methanol (0.5 ml.). Small samples of this solution were dispersed into a suitable volume of the opsin solution. This technique could result in the addition of up to $5 \%$ of methanol to the regeneration mixture, but no adverse effects were observed. Regeneration was measured by the rise in $E_{500}$, which always reached a maximum within $3 \mathrm{hr}$. at 15-20 at $\mathrm{pH} 6 \cdot 4$. The reference sample contained no added retinal. The final rhodopsin content was measured by the addition of neutral l $\mathrm{M}$-hydroxylamine to give a final concentration of $0.05 \mathrm{M}$, which converted the excess of 
retinal isomers into the corresponding oximes $\left(\lambda_{\max }\right.$. 355-365 $\mathrm{m} \mu$ ). Occasionally $\mathrm{NaBH}_{4}$ (approx. $0.5 \mathrm{mg} . / \mathrm{ml}$. of solution) was used in place of hydroxylamine. Neither of these reagents at the stated concentrations changed the spectrum of the rhodopsin chromophore.

To calculate the original concentration of opsin, a sample was incubated with excess of 11-cis-retinal for $3 \mathrm{hr}$. at $20^{\circ}$. After the addition of hydroxylamine to $0.05 \mathrm{~m}$, the rhodopsin concentration in $\mathrm{m} \mu \mathrm{moles} / \mathrm{ml}$. was a direct measure of the opsin concentration in the original sample.

To calculate the purity of the 11-cis-retinal fraction, a sample was incubated with an excess of opsin. The concentration of the added retinal was measured by $E_{380}$ within 30sec. of incubation. Alternatively, an identical sample of the added retinal was dispersed into the same volume of aq. $2 \%(w / v)$ digitonin, and the $E_{380}$ was recorded. After maximum regeneration had occurred $(3 \mathrm{hr}$.), hydroxylamine was added to $0.05 \mathrm{M}$. For a $100 \%$ conversion of 11 -cis-retinal into rhodopsin, $E_{500}$ should rise to 1.87 times the original $E_{380}$ value. The maximum experimental value is approx. 1.7 (Brown \& Wald, 1956), and therefore this value was taken to represent the total conversion of a pure 11-cisretinal sample. Spectroscopic estimations of the purity of 11-cis-retinal samples were performed by the methods of Brown \& Wald (1956).

Synthesis of tritiated rhodopsin and tritiated dihydro. metarhodopsin II. Tritiated retinal (approx. 5·3 $\mu$ moles) containing $40-50 \%$ of 11-cis-retinal was incubated for $2 \mathrm{hr}$. with opsin (3.5 $\mu$ moles) in approx. $100 \mathrm{ml}$. of $2 \%(\mathrm{w} / \mathrm{v})$ digitonin in 0.067 $\mathrm{M}$-sodium phosphate buffer, pH 6.4. After this period, no further regeneration of rhodopsin was observed on addition of $\mathbf{0 . 5} \mu$ mole of opsin. Neutral $1 \mathrm{M}$-hydroxylamine was then added to a final concentration of $0.05 \mathrm{M}$, converting the excess of retinal isomers into the corresponding oximes $\left(\lambda_{\max }\right.$. 355-365 $\left.\mathrm{m} \mu\right)$. An estimated $2.45 \mu$ moles of rhodopsin was synthesized, assuming a molar extinction coefficient for rhodopsin in aqueous digitonin of 40600. The specific radioactivity of the 11-cis-retinal sample was approx. $2.7 \times 10^{7}$ counts $/ \mathrm{min} . / \mu$ mole, and therefore $6.6 \times 10^{7}$ counts $/ \mathrm{min}$. had been incorporated into rhodopsin.

The rhodopsin solution was treated with $\mathrm{NaBH}_{4}$ (10$15 \mathrm{mg}$.) and irradiated with intense white light to give tritiated dihydrometarhodopsin II $\left(\lambda_{\max } .333 \mathrm{~m} \mu\right)$. This was confirmed by a difference spectrum against an unbleached reference sample. The mixture was freeze-dried for subsequent purification; the solid was stored at $-15^{\circ}$.

Purification of tritiated dihydrometarhodopsin II. The freeze-dried solid containing approx. $2 \cdot 45 \mu \mathrm{moles}$ of tritiated dihydrometarhodopsin II $\left(6 \cdot 6 \times 10^{7}\right.$ counts/min.) was stirred vigorously with two $150 \mathrm{ml}$. portions of methanol and two $75 \mathrm{ml}$. portions of ether, all operations being performed under $\mathrm{N}_{2}$ at $5-10^{\circ}$. The suspension was centrifuged and the solid (A) retained. Measurement of the total $E_{355}$ in the washings and also the total radioactivity indicated that over $95 \%$ of the excess of retinal in the regeneration mixture had been extracted as retinal oxime.

Basic hydrolysis of tritiated dihydrometarhodopsin II. About 2-10mg. of $\epsilon-N$-retinyl-lysine (measured by the total $E_{325}$, assuming a molar extinction coefficient of 52000 in methanol) in $0.5 \mathrm{ml}$. of methanol was added to a hydrolysis vial. The solvent was removed by passing a stream of $\mathrm{O}_{2}$-free $\mathrm{N}_{2}$ over the sample, the purified gas being obtained by bubbling commercial $\mathrm{O}_{2}$-free $\mathrm{N}_{2}$ through alkaline anthraquinone solution. A known fraction of solid (A) containing tritiated dihydrometarhodopsin II (approx. $1 \times 10^{7}$ counts $/ \mathrm{min}$.) was suspended in $1.0 \mathrm{ml}$. of water and then added to the vial together with $2.0 \mathrm{ml}$. of $\mathrm{O}_{2}$-free $7 \cdot 5 \mathrm{~N}-\mathrm{NaOH}$. The vial was evacuated and flushed at least five times with $\mathrm{O}_{2}$-free $\mathrm{N}_{2}$ and finally sealed under $\mathrm{N}_{2}$. The contents were placed in the dark at $110^{\circ}$ for $24 \mathrm{hr}$. and shaken occasionally.

Analysis and extraction of hydrolysates. Spectroscopic analysis of hydrolysates was performed by addition of a sample to aq. $2 \%(w / v)$ digitonin solution. Samples of this solution could also be measured for radioactivity or analysed for radioactive components by thin-layer chromatography, or both.

To extract the retinylamino acids and related components, the hydrolysate was cooled to $0^{\circ}$ and $6 \mathrm{~N}-\mathrm{HCl}$ was slowly added to give final $\mathrm{pH} 7 \cdot 5-8 \cdot 0$. The mixture was then freeze-dried and extracted for $20 \mathrm{~min}$. with $40 \mathrm{ml}$. of $10-50 \%(\mathrm{v} / \mathrm{v})$ chloroform in methanol at $10^{\circ}$ by vigorous stirring under $\mathrm{N}_{2}$. This procedure recovered up to $40 \%$ of the $\epsilon-N$-retinyl-lysine present in post-hydrolysis mixtures. The extract was evaporated to dryness and taken up in methanol.

Distribution of radioactive components in hydrolysate extracts. Samples of the extracts in methanol were applied as a band to analytical thin layers and developed in solvent $1,2,3,4$ or 5 . $\epsilon-N$-Retinyl-lysine was present on all chromatograms and could be detected by fluorescence and ninhydrin reaction at the edge of the layer. The remaining regions of the chromatogram were scanned for radioactivity as described above.

Hydrogenation of hydrolysate extracts and analysis of products. Methanolio samples of the extracts were hydrogenated by the method described for $\epsilon-N$-retinyl-lysine, with $20 \mathrm{mg}$. of $10 \%$ palladium on charcoal. The product was analysed for distribution of radioactivity by thin-layer chromatography, as described for the starting material. The position of $\epsilon$-PHRL was located with ninhydrin.

Isolation of radioactive fractions. The major radioactive component in the hydrogenated extracts was isolated by preparative thick-layer chromatography. The layers were developed in solvent 1 and the region corresponding to $\epsilon-P H R L$, which contained the radioactive band, was eluted with aq. $\mathrm{NH}_{3}$ soln. (sp.gr. 0.88)-methanol (1:10, v/v). Approx. $50 \%$ of the added radioactivity was present in the purified sample.

Preparation of DNP derivatives of unknown radioactive components. Traces of $\mathrm{NH}_{3}$ were removed from samples by evaporation in vacuo. The preparation, purification and analysis of the DNP derivatives were identical with those described for the derivatives of $\alpha$-PHRL and $\epsilon$-PHRL. A sample containing 150000 counts/min. was treated with 1-fluoro-2,4-dinitrobenzene and 141000 counts/min. were subsequently detected in the basic ether extract. On thinlayer chromatographic analysis this extract gave 100000 110000 counts/min. in the region of bis-DNP- $\epsilon$-PHRL.

Effect of $\mathrm{pH}$ on the reaction of all-trans-retinal with poly-L-lysine or L-lysine. all-trans-Retinal (approx. $5 \mathrm{mg}$.) was dissolved in $1 \mathrm{ml}$. of methanol containing $10 \mathrm{mg}$. of digitonin. Samples $(20 \mathrm{ml}$.) of aq. $2 \%(\mathrm{w} / \mathrm{v})$ digitonin were adjusted to $\mathrm{pH} 6 \cdot 4,7 \cdot 5,8 \cdot 3$ and 10.0 with triethylamine, and the retinal concentrate was then added to each until the extinction at $386 \mathrm{~m} \mu$ was $1 \cdot 2$. Each sample thus contained $0 \cdot 64 \mu$ mole of all-trans-retinal, assuming a molar extinction 
cosfficient in aqueous digitonin of 37700 . The absorption maxime at zero time were recorded and then $1.0 \mathrm{ml}$. of an aqueous solution containing $2.0 \mathrm{ml}$. of poly-L-lysine hydrobromide $(0 \cdot 79 \mu \mathrm{mole} / \mathrm{ml}$.) was added, after adjustment to the same pH. By taking a value of 2600 for the molecular weight of poly-L-lysine, it was calculated that each molecule contained approx. 20 free e-amino groups. Therefore the ratio of free $\epsilon$-amino groups/molecule of all-trans-retinal in the reaction mixtures was $25: 1$. The reactions were allowed to proceed for $4 \mathrm{hr}$., and the new absorption maxima were then recorded. Schiff-base formation was measured by adjusting a sample of each reaction mixture to $\mathrm{pH} 4.0$ with $1 \mathrm{~N} \cdot \mathrm{HCl}$ and observing any shift in the absorption maxima to longer wavelengths. A similar experiment was performed with L-lysine hydrochloride $(2.9 \mathrm{mg}$.) in place of poly-Llysine, to give a molar ratio of lysine to all-trans-retinal of 25:1. The Schiff-base formation in these experiments was detected only above $\mathrm{pH} \mathbf{8 \cdot 3}$.

Measurement of Schiff-base formation between all-trans. retinal and thodopsin at $\mathrm{pH} 7 \cdot 5$. A $20 \mathrm{ml}$. portion of rhodopsin solution $\left(E_{500} 1.0\right)$ in aq. $2 \%(\mathrm{w} / \mathrm{v})$ digitonin and $0.05 \mathrm{M}$ sodium phosphate buffer, $\mathrm{pH} 7 \cdot 5$, was mixed with an equimolar amount of all-trans-retinal $\left(E_{387} 0.93\right)$. A control solution containing no rhodopsin was also prepared. The solutions were divided into two and left for $5 \mathrm{~min}$. at $20^{\circ}$. One of the samples was then irradiated with intense white light for $2 \mathrm{~min}$. in the presence of $5 \mathrm{mg}$. of $\mathrm{NaBH}_{4}$, and the other was treated with $\mathrm{NaBH}_{4}$ 5 min. after irradiation. Solutions were extracted with three $5 \mathrm{ml}$. lots of ether to recover retinol, and the extracts, after evaporation to dryness in vacuo, were taken up in methanol. The amount of retinol present was measured by $E_{325-835}$, by assuming a molar extinction coefficient in methanol of 52800 . The recovery of retinal as retinol in the control solutions was greater than $60 \%$. The experiments once again showed that under the conditions described above no significant formation of Schiff bases occurred.

Action of hydroxylamine on $\epsilon-\mathrm{N}$-retinylidenelysine. A methanolic solution of $\epsilon-N$ sretinylidenelysine $\left(E_{440-450}\right.$ at pH 4.0 1.3) was adjusted to $\mathrm{pH} \theta .5$ or 8.5 with triethylamine or HCl. To samples $(3.0 \mathrm{ml}$.), $0.03 \mathrm{ml}$. of a neutralized $1 \mathrm{~m}$-hydroxylamine solution was added, giving a final concentration of $0.01 \mathrm{~m}$. Oxime formation was indicated by a shift of the absorption maximum to $356 \mathrm{~m} \mu$. Acid-base properties of this solution were investigated by the addition of $1 \mathrm{~N}-\mathrm{HCl}$ or triethylamine to $\mathrm{pH} 2.0$ or 10.0 respectively. A portion (approx. $1 \mathrm{mg}$.) of $\mathrm{NaBH}_{4}$ was also added to a sample of the hydroxylamine-reaction product, thus converting residual $\epsilon-N$-retinylidenelysine into $\epsilon-N$-retinyl-lysine. No c- $N$-retinyl-lysine could be detected when measured either by a rise in $E_{395-835}$ or by thin-layer chromatography in solvent 1. This experiment showed that hydroxylamine had quantitatively converted the Schiff-base analogue into the corresponding oxime.

Measurement of the molar extinction coefficient of the DNP derivative of e-PHRL. A sample of tritiated $\epsilon-N$-retinyl. lysine was isolated by thin-layer ohromatography in solvent 1,2 or 3 . The fluorescent band was immediately eluted with methanol-aq. $\mathrm{NH}_{3}$ goln. (sp.gr. 0.88) $(19: 1, \mathrm{v} / \mathrm{v})$, and the extract was analysed quantitatively for $E_{325-330}$ and also for radioactivity. This sample was then hydrogenated as described above in the preparation of $\epsilon$-PHRL. It was assumed that the specific radioactivity of the $\epsilon$.PHRL thus formed was identical with that of the starting material, $\epsilon-N$-retinyllysine. After removal of traces of $\mathrm{NH}_{3}$ by evaporation in vacuo, the DNP derivative was prepared and extracted as described above for e-PHRL. The DNP derivative was purified by thin-layer chromatography in solvent $A$ or $C$, and the yellow band was immediately eluted with $0 \cdot 1 \mathrm{~N}$-acetic acid in methanol. The extract was analysed quantitatively for $E_{355-360}$, and also for radioactivity. The measurement of the molar extinction coefficient is included in the Results and Discussion seotion. The value showed a maximum variation of $\pm 6 \%$.

Measurement of the relative molar extinction coefficients of the DNP derivatives of $\alpha-P H R L$. The preparations of tritiated $\alpha$-PHRL and its DNP derivatives are described above. The ether extract containing the DNP derivatives was subjected to thin-layer chromatography in solvent $\boldsymbol{A}$ or $C$, and the two yellow bands were eluted with $0 \cdot 1 \mathrm{~N}$-acetic acid in methanol. Apart from traoes of 1-fluoro-2,4dinitrobenzene and 2,4-dinitrophenol, no other coloured components could be detected on chromatograms. Similarly, most of the radioactivity (85-90\%) was associated with the two isolated yellow bands. The extracts were analysed quantitatively for $E_{345-355}$ and also for radioactivity. The measurement of the relative molar extinction coeffioients is described in the Results and Discussion section.

We thank F. Hoffmann-La Roche and Co. of Basle, Switzerland, for a kind gift of 11-cis-retinal. We are also grateful to the management of Funtley Abattoir, Fareham, Hants., for their co-operation in supplying cattle retinae. We thank Professor K. A. Munday for his kind interest and encouragement. P.T.B. thanks the Scienoe Research Council and P.B.D. thanks the Medical Researoh Council for maintenance grants. We thank the Soience Research Council for a grant towards the purchase of a scintillation counter.

\section{REFERENCES}

Abrahamson, E. W., Erhardt, F. \& Oestroy, S. E. (1966). Biochim. biophys. Acta, 112, 256.

Akhtar, M., Blosse, P. T. \& Dewhurst, P. B. (1965). Life Sci. 4, 1221.

Akhtar, M., Blosse, P. T. \& Dewhurst, P. B. (1967). Chem. Commun. p. 631.

Attenburrow, J., Cameron, A. F. B., Chapman, J. H., Evans, R. M., Hems, B. A., Jansen, A. B. A. \& Walker, T. (1952). J. chem. Soc. p. 1094.

Ball, S., Goodwin, T. W. \& Morton, R. A. (1948). Biochem. J. 42, 516.

Blosse, P. T. (1967). Ph.D. Thesis: University of Southampton.

Bownds, D. (1967). Nature, Lond., 216, 1178.

Bownds, D. \& Wald, G. (1965). Nature, Lond., 205, 254.

Brown, P. K. \& Wald, G. (1956). J. biol. Chem. 222, 865.

Dewhurst, P. B. (1967). Ph.D. Thesis: University of Southampton.

Matthews, R. G., Hubbard, R., Brown, P. K. \& Wald, G. (1963). J.gen. Physiol. 47, 215.

Pitt, G. A. J., Collins, F. D., Morton, R. A. \& Stok, P. (1955). Biochem. J. 59, 122.

Shields, J. E., Dinovo, E. C., Henriksen, R. A., Kimbel, R. L. \& Millar, P. G. (1967). Biochim. biophys. Acta, 147, 238. Wald, G. (1948). J. gen. Physiol. 81, 489. 